\title{
O PROCESSO DE APRENDIZAGEM DO INDIVÍDUO NO CONTEXTO ORGANIZACIONAL
}

\section{ARTIGO ORIGINAL}

SILVA, Lilian Reis da ${ }^{1}$

SILVA, Lilian Reis da. O processo de aprendizagem do indivíduo no contexto organizacional. Revista Científica Multidisciplinar Núcleo do Conhecimento. Ano. 06, Ed. 10, Vol. 08, pp. 17-30. Outubro 2021. ISSN: 2448-0959, Link de acesso: https://www.nucleodoconhecimento.com.br/educacao/aprendizagem-do-individuo, DOI: 10.32749/nucleodoconhecimento.com.br/educacao/aprendizagem-do-individuo

\section{RESUMO}

O presente artigo, elaborado através de pesquisa bibliográfica, tem como questão norteadora a forma como os indivíduos aprendem e interagem no contexto das organizações. Tendo como objetivo abordar a forma como a aprendizagem individual colabora para a aprendizagem organizacional entre os indivíduos. A partir da literatura analisada, verificou-se que aos saberes e conhecimentos adquiridos individualmente pelas pessoas devem somar-se as habilidades de comunicação, interação e compartilhamento com os colegas, no âmbito das organizações, para que juntos aprendam a cultura, o sistema interno, os objetivos e as práticas inerentes à mesma, no sentido da conquista das metas existentes.

Palavras-chave: Capital humano, Conhecimento, Competências, Desempenho profissional, Aprendizagem Organizacional.

\section{INTRODUÇÃO}

Ao longo da vida profissional, todos os indivíduos têm inúmeras oportunidades de aprendizado além daquela convencional - e individual - como, por exemplo, as

${ }^{1}$ Pós-graduada em Gestão Empresarial, Economista, Técnica Contábil.

RC: 99918

Disponível em: https://www.nucleodoconhecimento.com.br/educacao/aprendizagemdo-individuo 
novas formas de trabalhar, que costumam ser diferentes de uma empresa para outra. Tal aprendizado, pode ocorrer, também, a partir de novas leituras, cursos de especialização ou na identificação de vídeos na internet, sobre temas inerentes à área de atuação. Há, ainda, o próprio networking.

Diante do volume de informações e modernizações que a sociedade global vive, Bezerra e Oliveira (2006, s.p.) referem Guns (1998, p.7) para confirmar que o volume de informações na atualidade é tão grande que "executivos, gerentes e trabalhadores de linha de frente enfrentam, igualmente, quantidades gigantescas de informações".

Por sua vez, a valorização dos indivíduos em uma sociedade que hoje já reconhece que o capital humano é o bem mais precioso dentro das organizações (CHIAVENATO, 2020), os trabalhadores deixaram aquele papel de simples executores de tarefas previamente definidas, passando ao papel de clientes internos, que requerem constantes atualizações para melhor desempenharem suas funções, cujos resultados devem ir ao encontro das metas estabelecidas pela direção de tais organizações.

Tal realidade - nem tão recente - traz a todos o conceito sobre aprendizagem organizacional, que, segundo Guns (1998, p. 33, apud BEZERRA e OLIVEIRA, 2006, s.p.), consiste em adquirir "conhecimentos, habilidades, valores, convicções e atitudes que acentuem a manutenção, o crescimento e o desenvolvimento da organização".

Diante disso, o objetivo deste artigo é abordar a forma como a aprendizagem individual colabora para a aprendizagem organizacional entre os indivíduos.

\section{OS PROCESSOS DE APRENDIZAGEM DOS INDIVÍDUOS}

A aprendizagem consiste no ato do indivíduo adquirir conhecimentos, já que "é da natureza do conhecimento que ele mude rápido e que as certezas de hoje se tornem os absurdos de amanhã" (DRUCKER, 1999, p.121).

RC: 99918

Disponível em: https://www.nucleodoconhecimento.com.br/educacao/aprendizagemdo-individuo 
Aprender em um mundo em constante mutação não é algo fácil, sendo fundamental - em tempos modernos - que profissionais de todas as áreas se mantenham em constante aprendizagem. Fleury e Fleury (2001, apud MENEZES et al., sem data, p. 2) ensinam que "a aprendizagem é considerada como um processo de mudança, desencadeada por diversos estímulos, intermediado por emoções, que podem vir ou não a manifestar-se em mudança no comportamento do indivíduo".

Segundo o Dicionário Houaiss da Língua Portuguesa (HOUAISS, 2015, p. 74), aprendizagem é "ato, duração e experiência, ação de aprender um ofício ou profissão" e aprender é "adquirir conhecimento habilidade prática, ter melhor compreensão de (algo), pela intuição, experiência ou convivência [...]”.

Para Bruni; Turrioni e Stano (2005, p.190), trata-se de um processo psicológico que é fundamental à sobrevivência humana, que lhe permite adaptar-se ao meio em que vive, e inclusive, conquistando crescimento moral, intelectual e profissional. Já Menezes et al. (sem data, p.2) reportam Abbad e Borges-Andrade (2004, p.238), para destacar que "a aprendizagem é um processo psicológico que ocorre no nível do indivíduo.

Sob a ótica de Júlio (2003), a grande questão relativa ao aprendizado consiste na necessidade de as pessoas aprenderem a aprender, para que possam aprender sempre. Ocorre que para aprender a aprender os indivíduos buscam o conhecimento através da informação, sendo esta que, por sua vez, permite às pessoas que atinjam novos conhecimentos através da escolha, seleção, assimilação e associação, com o objetivo de melhorar e aprender a aprender. $O$ fato é que enquanto o conhecimento é o resultado da seleção das informações, que se acumulam, isto é, o conhecimento de uma pessoa se constrói mediante aquilo que ela escolhe com base nas informações que obtém e que nelas passa a confiar (JULIO, 2003).

A estes fatos, soma-se o surgimento da internet, que permite aos indivíduos obterem as mais diferentes conteúdos e informações, inclusive em tempo real, apesar de ter 
sido cada vez mais comum que sejam localizados muitos materiais que não correspondem à realidade e com isso, deixam de agregar qualquer valor aos internautas.

Segundo Bruni et al. (2005, p.190), o aprendizado ocorre, efetivamente, a partir do momento em que o indivíduo passa por determinada experiência, já que as inúmeras conexões cerebrais que ocorrem permitem que a pessoa associe os fatos acontecidos em seu entorno.

Nesta perspectiva, Senge (2002, p.32) defende que "todo o aprendizado se relaciona à ação. O aprendizado nunca ocorre exclusivamente através do estudo passivo". Ainda Bruni et al. (2005) explicam ser por meio da interação entre as pessoas que os conhecimentos se expandem, individual e coletivamente. Outro aspecto relevante destacados por estes autores consiste nos tipos de aprendizagem que agregam saberes aos indivíduos, são eles: a aprendizagem formal ou multidisciplinar, e a aprendizagem informal, que se dá em todos os lugares e diferentes situações, a partir da observação das circunstâncias e da interação entre as pessoas.

Neste sentido, Menezes et al. (sem data, p.4) referem que a aprendizagem formal se dá com base em ações específicas relativamente às tarefas e objetivos a cumprir, contando essencialmente com "técnicas, métodos, condições e lugares especificados anteriormente e que possui o intuito de originar conhecimentos, atitudes, habilidades, comportamentos e ideias". Ainda segundo os autores, a aprendizagem formal dos indivíduos é elaborada sob um método contendo estruturas organizadas.

Por sua vez, está a aprendizagem informal, embora seja indiscutível a relevância da aprendizagem formal para os indivíduos, no contexto de suas vidas pessoais, na perspectiva do ambiente organizacional, as diferentes oportunidades e objetivos de cada empresa irão, por si, requerer que seus colaboradores detenham habilidades e 
conhecimentos distintos, adquiridos em atividades práticas, como ensinam Flach e Antonello (2010, apud MENEZES et al., sem data, p. 4).

Neste sentido, Menezes et al. (sem data, p.4) reportam Zerbini (2007), para defender que a aprendizagem informal consiste em processos pelos quais as pessoas observam conversas formais ou não informais, seja em reuniões de trabalho ou em ambientes descontraídos.

De outra forma, a aprendizagem informal a aprendizagem informal se dá quando uma pessoa tem - por iniciativa própria e para seu crescimento pessoal e profissional - a possibilidade de aprender novas visões e atitudes, que vão permitir a essa pessoa que faça a diferença em sua atuação profissional. É considerada aquela que "acontece fora dos currículos de cursos, programas educacionais ou workshops" (COELHO JÚNIOR e BORGES ANDRADE, 2008, apud MENEZES et al., s. d., p.4).

Outro processo no caminho do aprender a aprender é o reconhecimento das diferenças existentes entre as pessoas e o respeito por outras experiências de vida que estão registrados em suas mentes, as quais influenciam diretamente no comportamento dessas pessoas.

Neste sentido, Romanowski e Peranzoni (2011) reportam a importância de que as crianças sejam ensinadas, desde o início, a aceitarem as diferenças entre as pessoas, na forma como elas são, pensam e agem; as crianças devem ser ensinadas para o respeito com a diversidade, desde a tenra idade, indo até à vida adulta, e profissional, inclusive.

A importância de cada indivíduo aprender e reconhecer as diferenças entre as pessoas reside no fato de que, nas mais variadas regiões do país ou do mundo, existem diferenças na educação e formação recebida pelos indivíduos em casa ou na escola, diferem os hábitos, a visão sobre a vida e sobre situações e pessoas, difere a orientação sexual, e tantos outros aspectos são distintos, de um indivíduo para o outro (ROMANOWSKI e PERANZONI (2011).

RC: 99918

Disponível em: https://www.nucleodoconhecimento.com.br/educacao/aprendizagemdo-individuo 
Esta realidade requer que as diferenças na percepção, aprendizagem e comportamento das diferentes pessoas sejam aceitas por aqueles que a rodeiam, sendo muito importante para a estratégia de vida e dos negócios, pois o bom relacionamento e o respeito levam à maior produtividade e competitividade, no âmbito empresarial.

A este respeito, ainda Romanowski e Peranzoni (2011, s.p.) reportam Perreoud (2000) para afirmar que para aprender algo novo, cada pessoa precisa ser colocada em situações de aprendizado com frequência; além disso, que essas situações façam sentido para esse aprendiz, e que ele possa senti-las e mobilizar-se com e para elas.

\section{COMO DESENVOLVER O PROCESSO DE APRENDIZAGEM PERANTE AS COMPETÊNCIAS ORGANIZACIONAIS?}

\subsection{NAS ENTRELINHAS}

Todas as organizações - a despeito de sua estrutura ou segmento - contam com uma cultura organizacional que, segundo Chiavenato (2010), consiste nos "hábitos e crenças, estabelecidos por normas, valores, atitudes e expectativas, compartilhadas por todos os membros da organização. Ela se refere ao sistema de significados compartilhados por todos os membros e que distingue uma organização das demais".

Neste sentido, Wilbert e Cruz (2014, p. 2), ensinam que para uma empresa ser eficaz em seu segmento de atuação, é fundamental que o pensamento, valores e ações adotados em seu contexto estejam alinhados aos diferentes tipos de desafios diários, permitindo a conquista dos resultados esperados.

Ao longo do tempo, especialistas como Chanlat (1998) pesquisaram o comportamento humano, que não se resume apenas ao que é observável, uma vez que também se dá em função de outros aspectos, entre eles o desejar, o querer e a

RC: 99918

Disponível em: https://www.nucleodoconhecimento.com.br/educacao/aprendizagemdo-individuo 
pulsão do indivíduo. Da mesma forma, pesquisadores especializados em gestão organizacional elaboraram análises comportamentais nas organizações, cujo interesse foi observar os fenômenos humanos, em uma perspectiva da cultura psicanalítica, sugerindo três linhas de visão, que foram elencadas por Chanlat (1998) e outros autores:

a) linha de visão do grupo: vista como um sistema social de defesa contra a angústia e depressão, que analisa o comportamento despersonificado que até hoje inspira numerosos trabalhos (CHANLAT, 1998 apud JAQUES);

b) linha de visão do dirigente: uma segunda linha de pesquisa que procura destacar não apenas o papel e a importância que o imaginário exerce nas ações dos dirigentes das empresas, mas também as conseqüências de sua incidência sobre as organizações (CHANLAT, 1998 apud LEVINSON);

c) linha de visão da organização: uma linha que possui uma abordagem na psicologia social, onde vê a relação homem versus conflitos, elucidando até hoje o que - na organização do trabalho - entra em conflito com o funcionamento do aparelho psíquico (CHANLAT, 1998 apud DEJOURS).

Esses trabalhos visam à necessidade da tomada de consciência para compreensão da vida organizacional, importante ferramenta de gestão. É através dessa aprendizagem que podemos valorizar a vida interior e a afetividade que estão presentes na vida organizacional $\mathrm{e}, \mathrm{o}$ quanto as relações humanas são fundamentalmente marcadas pelas necessidades e vontades (SOUZA, 2016).

\subsection{COMPETÊNCIA}

A busca pela aprendizagem nas organizações adequando seu conhecimento, sua capacidade para determinada atividade e seu poder de decisão são os elementos necessários ao aumento das competências dos colaboradores nas organizações, já que, para cada cargo assumido, é preciso que todo o processo de aprendizagem esteja bem claro, permitindo ao trabalhador um bom desempenho, e resultados dentro do esperado (CROZATTI, 1998).

Segundo o Minidicionário Aurélio da Língua Portuguesa (FERREIRA, 2008, p. 249), o termo competência é definido como: "capacidade para resolver qualquer assunto,

RC: 99918

Disponível em: https://www.nucleodoconhecimento.com.br/educacao/aprendizagemdo-individuo 
aptidão, idoneidade." Com base nessa definição, observa-se que competência revela seu poder quando apreendida, ou seja, aprendida, compreendida e entendida, e quando há transformações do mundo do trabalho, quer seja nas empresas, quer seja na sociedade.

Definir tópicos individuais necessários ao bom desempenho em cada ocupação não é o suficiente para que ocorram inovações ou que sejam desenvolvidas novas habilidades para as empresas. O cargo e a ocupação definem a qualificação, ou os saberes ou os conhecimentos de cada indivíduo podem ser classificados pelo sistema educacional. Já o conceito de competência procura o caminho da proatividade, estar sempre à frente antecipando e dominando o que está acontecendo e o que estar por vir, não se limita, portanto, a um estoque de conhecimentos teóricos e empíricos detidos pelo indivíduo, assim como não se encontra implícita na tarefa (EBERT; POSSAMAI e SIMON, 2017).

Vendo a competência como inteligência prática dos conhecimentos adquiridos e os transformados, surge um novo padrão de competência, apresentados por Fleury e Oliveira Júnior (2001, apud ZARIFIAN, 2001):

a) necessidade de se antecipar aos fatos e às situações: as quais podem - de alguma forma - tumultuar o bom andamento das atividades e a capacidade de resolver as situações e problemas, para garantir o bom andamento do trabalho;

b) necessidade de comunicação e entendimento: do objetivo organizacional usando de empatia, para o alinhamento e partilhamento da cultura organizacional e cumprimento das normas da empresa. Neste sentido, Jean François Chanlat (1998) explica que a comunicação é absolutamente necessária, significando inclusive que - na maior parte do tempo - significa transmitir informação, sendo possível essa comunicação de várias maneiras: por meio de atitudes, de gestos, de modos de vestir, por meio de objetos colocados à nossa volta ou que manipulamos, de espaços organizados etc.;

c) noção de um serviço: entender um cliente independente de ser um cliente interno ou externo sempre precisa ser o foco central das atividades e para que isto ocorra, se faz fundamental a comunicação.

No âmbito de uma organização, o trabalho deixa de ser um conjunto de tarefas e passa a ser a soma das habilidades e competências utilizadas para resolver

RC: 99918

Disponível em: https://www.nucleodoconhecimento.com.br/educacao/aprendizagemdo-individuo 
diversas situações, já que são competências de cunho profissional cada vez mais rentáveis e complexas. Essa complexidade de situações torna o imprevisto cada vez mais comum no dia a dia (LIMA; ZAMBRONI-DE-SOUZA e ARAÚJO, 2015).

Ao se pensar na organização e a sua totalidade e não apenas nas atividades de produção, foco principal da análise (FLEURY e OLIVEIRA JÚNIOR, 2001, apud ZARIFIAN, 2001) observa-se a necessidade de introduzir duas outras menções ligadas às mutações no mundo do trabalho.

a) âmbito de atuação da organização: local, regional, nacional ou global: as mudanças de operações da empresa, nesses últimos anos em função do processo de globalização têm implicações significativas para a localização e a formação de competências não só em termos da organização. Percebe-se que essa visão está em todos os níveis (com diferentes ponderações e significações), fazendo parte da competência individual;

b) antes da visão estratégica: ficava no topo das organizações, mas atualmente deve estar em diferentes níveis com significação e critério distintos, compondo o perfil da competência individual.

A competência do indivíduo não é um estado, não é apenas um conhecimento exato, mas a coloca como resultado do cruzamento de três eixos: a formação da pessoa (sua biografia e socialização), sua formação educacional e sua experiência profissional (FLEURY e FLEURY, 2004, apud LE BOTERF, 1997).

A competência é um saber agir responsável com tal reconhecido pelos outros. Surge como: saber aprender, saber se engajar, assumir responsabilidade, ter visão estratégica, agregando valor econômico para a organização e valor social para o indivíduo.

As competências geram valor de cunho econômico para as organizações, assim como o devido valor social ao indivíduo; assim, podemos dizer que a competência organizacional é um portfólio de competências, o físico (infraestrutura), financeiro, intangível, corporativo (os recursos humanos), sendo esse último o que acreditamos ser o grande diferencial que cria as vantagens competitivas e dessa maneira, devemos ter estratégias competitivas dadas por esses recursos. Segundo Fleury e 
Fleury (2004), "um recurso é algo que a organização possui ou tem acesso, mesmo que esse acesso seja temporário [...] uma competência é construída a partir de um conjunto de 'blocos' denominados recursos".

Competência é a inteligência de conciliar, misturar e incluir recursos em produtos e serviços. A competitividade de uma organização estaria totalmente ligada na interação entre competência organizacional e estratégia competitiva dessa maneira, a abordagem dos recursos faz o processo de formulação da estratégia e a formação de competências formarem um círculo que se retroalimenta (FLEURY e FLEURY, 2004).

As competências essenciais oferecem reais benefícios aos consumidores, benefícios esses que são difíceis de serem imitados, e que dão acesso a diferentes mercados, sendo que, quando a empresa define sua estratégia competitiva, ela acaba identificando as suas competências essenciais do negócio e as competências necessárias de cada função - as competências organizacionais (FLEURY e FLEURY, 2004).

Nessa perspectiva, verifica-se que as empresas de diversas competências organizacionais (competências coletivas associadas às atividades-meio e às atividades-fim) em diversas áreas; contudo, apenas algumas são as competências essenciais, ou seja, são aquelas que as diferenciam e que the garantem uma vantagem competitiva sustentável diante das outras organizações. Para ser considerada uma competência essencial, esta deve estar ligada diretamente aos processos de aprendizagem organizacional, que dá o foco e reposiciona as estratégias competitivas (FLEURY e FLEURY, 2004).

Existem três tipos de estratégia que podem ser adotadas pelas organizações, por meio das quais as empresas competem no mercado, conforme Fleury e Fleury (2004):

RC: 99918

Disponível em: https://www.nucleodoconhecimento.com.br/educacao/aprendizagemdo-individuo 
a) excelência operacional: empresas que competem baseadas no custo, oferecendo aos seus clientes produtos com o melhor preço e atendimento adequado;

b) inovação no produto: empresas que oferecerem aos seus clientes produtos de ponta, inovando sempre;

c) orientada para clientes: característica de empresas voltadas a atender a demanda de clientes específicos, e antecipar as necessidades desses clientes, em função de sua proximidade com os mesmos.

Uma vez definida a estratégia competitiva, a empresa consegue identificar as competências essenciais do negócio, assim como as competências necessárias a cada função. Essa prática permite que sua diretoria passe do nível estratégico para o nível de formação das competências do indivíduo, competências essas categorizadas por Fleury e Oliveira Júnior (2001) em três grandes blocos que envolvem a relação do indivíduo com toda a organização:

a) competências de negócio: relacionadas ao negócio em si, seu mercado, clientes, concorrentes;

b) competências técnico-profissionais: habilidades específicas para a realização de determinada operação;

c) competências sociais: competências necessárias para interagir com as pessoas, entre elas a competência interdisciplinar necessárias a acordos, à comunicação, à liderança, e ao respeito às culturas distintas.

A comunicação é de suma importância pois garante o entendimento das mensagens pelos demais membros da organização; consiste na capacidade de expressar ideias de modo claro, utilizando técnicas de comunicação apropriadas à cada situação (CHIAVENATO, 2000).

Por meio da comunicação deve-se ter a capacidade de discutir, estimular e influenciar positivamente outras pessoas a colaborarem, efetivamente, para que os objetivos organizacionais sejam atingidos, conduzindo processos de obtenção de consenso, focando em resultados satisfatórios para as partes envolvidas e, principalmente, para a organização. Tais ferramentas são válidas para situações externas e internas, como por exemplo a forma ideal de argumentar, de modo que 
permita a persuasão das pessoas na venda de ideias e aceitar pontos de vista divergentes de sua visão inicial (CROZATTI, 1998).

O trabalho em equipe deve criar e trabalhar com grupos de pessoas que detenham habilidades e conhecimentos diversos e complementares, propiciando o surgimento da sinergia, que é a habilidade de manter tais grupos trabalhando em conjunto eficientemente, controlando participações excessivas e convidando membros silenciosos a participar, resolvendo conflitos (CHIAVENATO, 2000).

As discussões sobre a aprendizagem em organizações enraízam-se mais fortemente na perspectiva intelectual, evidenciando, as mudanças comportamentais. A forma como as pessoas manifestam e desenvolvem as competências fundamentais dentro da organização e a seu projeto profissional, é algo que se dá somente por meio do processo de desenvolvimento de suas competências (CHIAVENATO, 2000). Trata-se de um conjunto de situações de aprendizagem que podem levar à transformação do aprendizado em competências; como resultado, ocorrerá a soma de valor tanto para a pessoa quanto para a organização.

É um processo que pode ocorrer em diferentes níveis, como destacam Fleury e Fleury (2004):

a) ao nível individual: que é onde ocorre primeiro, e como já citado, em um indivíduo que é carregado de emoções positivas ou negativas, por meio dos caminhos que percorreu;

b) ao nível grupal: onde a aprendizagem pode vir a se constituir em um processo social e coletivo, sendo que para compreendê-lo é importante entender como é o aprendizado do grupo, como são integradas as crenças individuais com o grupo e, como transformam esse compartilhamento em ações, além do desejo de pertencer ao grupo, que pode constituir um elemento motivacional ao processo de aprendizagem;

c) em nível organizacional: o processo de aprendizagem individual, de compreensão e interpretação compartilhados pelo grupo, torna-se institucionalizado e conhecido em vários mecanismos organizacionais, ou seja, estrutura, regras, procedimentos, e até mesmo em elementos simbólicos, já que, assim como o indivíduo, as organizações também expandem as memórias que possuem informações e as recuperam.

RC: 99918

Disponível em: https://www.nucleodoconhecimento.com.br/educacao/aprendizagemdo-individuo 
Nesta etapa, cabe analisar os processos de aprendizagem. No que se refere ao processo de aprendizagem organizacional, é do tipo que implica na elaboração de mapas de conhecimento, que possibilitem compreender o que ocorre no ambiente externo e interno à organização, assim como na determinação de novos procedimentos, que comprovam a efetividade do aprendizado (FLEURY e FLEURY, 2004).

Para isto, as organizações contam com seus sistemas de conhecimento e memórias, que lhes permite desenvolverem rotinas e procedimentos para lidar com os problemas. Tais procedimentos são incorporados de forma visível na memória organizacional.

A mudança em processo, estruturas ou procedimentos são indicadores de que a aprendizagem ocorreu, somando-se a facilidade desse conhecimento ser recuperado pelos membros da organização. Segundo Fleury e Fleury (2000), "é o conhecimento tácito, às vezes inconsciente, que se apoia na memória organizacional". Neste sentido, o processo de aprendizagem possui muitas facetas:

a) "Aprendizagem organizacional é um processo de identificação e correção de erros" (ARGYRIS, 1997, p.116 apud FLEURY e FLEURY, 2000, p. 9);

b) "Aprendizagem organizacional significa um processo de aperfeiçoar as ações pelo melhor conhecimento e compreensão" (FIOL E LYLES, 1985, p.803 apud FLEURY e FLEURY, 2000, p. 9);

c) "organizações que aprendem são organizações capacitadas em criar, adquirir e transferir conhecimentos e modificar seus comportamentos para refletir esses novos conhecimentos e 'insights'" (GARVIN, 1993, p.80 apud FLEURY e FLEURY, 2000, p.9);

d) "Uma organização está continuamente expandindo sua capacidade de criar o futuro" (SENGE, 1990, p.14 apud FLEURY e FLEURY, 2000, p.9).

Uma organização aprende quando sua capacidade de adaptação às mudanças é acelerada, constituindo o primeiro passo no processo de aprendizagem. $O$ desejo de aprender vai mais adiante: é inovador e frutífero.

RC: 99918

Disponível em: https://www.nucleodoconhecimento.com.br/educacao/aprendizagemdo-individuo 


\section{CONCLUSÃO}

Mediante a análise das teorias selecionadas para elaboração deste estudo, verificase que os processos de aprendizagem envolvem diferentes aspectos - tanto os pessoais quanto os profissionais, para que o aprendizado dentro das organizações se desenvolva dentro das perspectivas de sua direção.

Se por um lado as vivências pessoais, educação formal e caraterísticas da personalidade dos indivíduos colaboram para sua formação pessoal, constituem-se em elementos que irão somar-se às características, diretrizes e sistemas de trabalho existentes dentro das empresas, sendo necessário que cada trabalhador (a) se adapte da melhor forma, além de identificar a existências de possibilidades de expansão de suas habilidades e criatividade - ou não - conforme as expectativas organizacionais.

\section{REFERÊNCIAS}

BEZERRA, Alan André Aparecido; OLIVEIRA, Ednilson Barbosa de. Aprendizagem Organizacional: a organização que aprende. Artigo publicado em 06 jul 2006. Disponível em: [https://administradores.com.br/artigos/aprendizagem-organizacionala-organizacao-que-aprende]; acesso em 28 mar 2021.

BRUNI, Márcia; TURRIONI, João Batista; STANO, Rita de Cássia Trindade. Abordagens da aprendizagem no contexto organizacional. II Simpósio de Excelência em Gestão e Tecnologia - SEGeT'2005. p. 190-198. Disponível em: [https://www.aedb.br/seget/arquivos/artigos05/274 Abordagens\%20da\%20aprendiza gem\%20no\%20contexto\%20organizacional.pdf]; acesso em 28 mar 2021.

CHANLAT, Jean François. O indivíduo na Organização. 1.ed. São Paulo: Atlas, 1998, v.3.

CHIAVENATO, Idalberto. Recursos humanos - 0 capital humano das organizações. 11.ed. São Paulo: Atlas, 2020.

RC: 99918

Disponível em: https://www.nucleodoconhecimento.com.br/educacao/aprendizagemdo-individuo 
Gestão de pessoas: o novo papel dos recursos humanos nas organizações. 3.ed. Rio de Janeiro: Elsevier, 2010.

CROZATTI, Jaime. Modelo de Gestão e Cultura Organizacional - conceitos e interações. Caderno de Estudos, SP, FIPECAFI, vol. 10, n. 18, maio/ago 1998.

DRUCKER, Peter F. Administrando em Tempos de Grandes Mudanças. São Paulo: Pioneira, 1999.

EBERT, Luis Augusto; POSSAMAI, Cleide Tirana Nunes; SIMON, Vanessa Silveira. Perspectivas profissionais. Indaial: UNIASSELVI, 2017. Disponível em: [https://www.uniasselvi.com.br/extranet/layout/request/trilha/materiais/livro/livro.php? codigo=25048]; acesso em 03 abr 2021.

FERREIRA, Aurélio Buarque de Holanda. Miniaurélio: o minidicionário da língua portuguesa. 7.ed. Curitiba: Positivo, 2008.

FLEURY, Afonso C. C.; FLEURY, Maria Tereza Leme. Estratégias Competitivas E Competências Essenciais: Perspectivas Para A Internacionalização Da Indústria No Brasil. Gestão \& Produção, vol.10, n.2, p.129-144, ago. 2003. Disponível em: [https://www.scielo.br/j/gp/a/C8hMY4qXzCfGWd4v8VRwXJQ/?lang=pt]; acesso em 28 mar 2021.

FLEURY, M. Teresa Keme; OLIVEIRA JR., Moacir de M. (Coord.). Gestão estratégica do conhecimento: integrando aprendizagem, conhecimento e competências. São Paulo: Atlas, 2001.

GUNS, Bob. A organização que aprende rápido: seja competitivo utilizando o aprendizado organizacional. São Paulo: Futura, 1998. 
HOUAISS, Antonio; VILLAR, Mauro de Salles; FRANCO, Francisco Manoel de Mello. Pequeno Dicionário Houaiss da Língua Portuguesa. 1.ed. São Paulo: Moderna, 2015.

JULIO, Carlos Alberto. A Magia dos Grandes Negociadores. 1.ed. Rio de Janeiro: Elsevier, 2003.

LIMA, Claudia Maria Pereira de; ZAMBRONI-DE-SOUZA, Paulo César; ARAÚJO, Anísio José da Silva. A Gestão do Trabalho e os Desafios da Competência: uma Contribuição de Philippe Zarifian. Psicologia: Ciência e Profissão, vol. 35, n. 4, p. 1223-1238, 2015.

Disponível em: [https://www.scielo.br/j/pcp/a/xxL7S4fWDxwkKWmkB4rtTWp/abstract/?lang=pt]; acesso em 28 mar 2021.

MENEZES, Bárbara Sampaio de; CABRAL, Augusto Cézar De Aquino; SANTOS, Sandra Maria dos; SILVA, Maria Naiula Monteiro da. Aprendizagem individual no contexto organizacional: percepção dos estudantes da FEAAC - UFC. Artigo publicado nos Anais do ENGEMA - Encontro Internacional sobre Gestão Empresarial e Meio Ambiente. Disponível em: [http://engemausp.submissao.com.br/17/anais/arquivos/81.pdf]; acesso em 28 mar 2021.

PERRENOUD, Philippe. Dez novas competências para ensinar: convite à viagem. Porto Alegre: Artes Médicas, 2000.

ROMANOWSKI, Caroline Leonhardt; PERANZONI, Vaneza Cauduro. Educação para diversidade humana: respeito às diferenças $e$ valorização da singularidade. EFDeportes.com, Revista Digital. Buenos Aires - Año 16 - № 158 julho de 2011. Disponível em: [https://www.efdeportes.com/efd158/educacao-paradiversidade-humana.htm]; acesso em 03 abr 2021.

SENGE, Peter M. A Quinta Disciplina: Arte e Prática da Organização que aprende. 10. ed. São Paulo: Best Seller, 2002.

RC: 99918

Disponível em: https://www.nucleodoconhecimento.com.br/educacao/aprendizagemdo-individuo 
WILBERT, Alison; CRUZ, Hélio Alves da. Cultura e Clima Organizacionais: uma análise na empresa Novo Trigo de Balneário Camboriu/SC. XI SEGeT - Simpósio de Excelência em Gestão e Tecnologia, de 22 a 24 de outubro de 2014. Disponível em: [https://www.aedb.br/seget/arquivos/artigos14/45120574.pdf]; acesso em 28 mar 2021.

Enviado: Março, 2021.

Aprovado: Outubro, 2021. 